\title{
PROPAGAÇÃO DE ABACATEIRO CV. FUERTE POR ESTACAS HERBÁCEAS
}

\section{PROPAGATION OF AVOCADO CV. FUERTE BY HERBACEOUS CUTTINGS}

\author{
Ubirajara Ribeiro MINDÊLLO-NETO ${ }^{1}$ \\ Elcio HIRANO 2 \\ Charles Allan TELLES ${ }^{3}$ \\ Luiz Antonio BIASI ${ }^{4}$
}

\begin{abstract}
RESUMO
Este trabalho teve como objetivo avaliar o efeito de concentrações de ácido indolbutírico e tempo de imersão no enraizamento de estacas herbáceas de abacateiro cv. Fuerte. Estacas foram tratadas com concentrações de 0, 500, 1.000, 2.000 e 4.000 mg.L.' de AIB em dois tempos de imersão (5 segundos e 24 horas), de acordo com cada tratamento estudado. Todas as estacas foram colocadas em substrato areia, textura média, em bandejas de poliestireno expandido, contendo 72 células. Posteriormente, as bandejas contendo as estacas foram levadas para casa-de-vegetação com nebulização intermitente, onde permaneceram por 185 dias. A maior porcentagem de estacas enraizadas (47,5\%) foi obtida pelo método de imersão das estacas por 5 segundos na concentração de $500 \mathrm{mg}^{-L^{-1}} \mathrm{de} A \mathrm{IB}$. A imersão das estacas em água destilada promoveu enraizamento, independentemente do tempo de imersão. O enraizamento foi nulo quando as estacas foram imersas na solução hidro-alcoólica de AIB por 24 horas.

Palavras-chave: Persea spp, estaquia, ácido inbolbutírico, tempo de imersão.
\end{abstract}

\begin{abstract}
This work was done with the purpose to evaluate the effect of the indolbutyric acid (IBA) concentration and immersion time for rooting of herbaceous cuttings of avocado cv. Fuerte. The cuttings were treated with IBA at concentrations of $0,500,1.000,2.000$ and 4.000 mg. L- ${ }^{-1}$ of IBA in two immersion periods ( 5 seconds and 24 hours) according to each treatment. All cuttings tested were placed in a substrate with sand medium texture in expanded poliestirene trays with 72 cells. Afterward the treated cuttings were placed inside intermittent mist greenhouse for 185 days. The highest percentage of rooted cuttings (47,5\%) was obtained by immersion for 5 seconds at the concentration of $500 \mathrm{mg} \mathrm{LL}^{-1}$ of IBA. The immersion of cuttings in distilled water promoted the rooting regardless the immersion time. The rooting percentage was zero when the cuttings were immersed into hydro-alcoolic solution of IBA for 24 hours.
\end{abstract}

Key-words: Persea spp, cutting, indolbutyric acid, immersion time.

\footnotetext{
${ }^{1}$ Eng.. Agrônomo, M.Sc. Embrapa Transferência de Tecnologia/SNT Canoinhas, Rod. BR 280, km 219, Caixa Postal 317, CEP 89.460-000, CanoinhasSC.E-mail: ubirajara.encan@embrapa.br.

${ }^{2}$ Eng.ำ Agrônomo, Dr. Embrapa Transferência de Tecnologia/SNT Canoinhas-SC. E-mail: hirano.encan@embrapa.br.

${ }^{3}$ Eng.. Agrônomo, M.Sc. Programa de Pós-Graduação em Agronomia - Produção Vegetal. Universidade Federal do Paraná. Curitiba-PR. E-mail: agrotelles@yahoo.com.br.

${ }^{4}$ Eng. ${ }^{\circ}$ Agrônomo, Dr. Professor Adjunto do Departamento de Fitotecnia e Fitossanitarismo. Setor de Ciências Agrárias. UFPR. Caixa Postal 19.061. CEP 81531-990. Curitiba-PR. E-mail: biasi@ufpr.br. Bolsista de Produtividade em Pesquisa do CNPq. Autor para correspondência.
} 


\section{INTRODUÇÃO}

A propagação clonal de porta-enxertos de abacateiro é uma técnica que foi desenvolvida na Califórnia (FROLICH e PLATT, 1972), principalmente para propagação de porta-enxertos tolerantes à gomose. Entretanto, em algumas seleções e/ou cultivares, o enraizamento é muito baixo, podendo este fato ser explicado pela estrutura anatômica do caule das plantas, como a espessura do anel fibro-esclerenquimático, que pode atuar como uma barreira à emergência das raízes, podendo estar relacionado com a habilidade de enraizar, principalmente na raça antilhana, sendo pequena na raça mexicana (Gomes et al., 1973) e por fatores fisiológicos, como o balanço entre promotores e inibidores de enraizamento (MOHAMMED e SORHAINDO, 1984).

Segundo Reuvevi e Raviv (1976), o enraizamento é diferenciado entre as raças de abacateiro, sendo que as cultivares da raça mexicana enraízam melhor do que às cultivares da raça antilhana, e as da raça guatemalense apresenta enraizamento intermediário. Este fato pode ser de grande utilidade, principalmente em regiões sujeitas às geadas, como as do presente estudo, onde o uso de porta-enxertos das raças guatemalense e mexicana e/ou híbridas, como o abacateiro cv. Fuerte, provenientes da propagação clonal poderão ser usadas como porta-enxertos para indução à resistência ao frio da copa.

Para aumentar o enraizamento em estacas de abacateiro se tem recorrido a técnicas especiais, tais como a aplicação exógena de reguladores de crescimento, o estiolamento e o anelamento (KADMAN e BEN-YA'ACOV, 1965; MOHAMMED e SORHAINDO, 1984; SILVEIRA et al., 2004), entretanto, para algumas cultivares estas técnicas podem não ter influência. Entre os reguladores de crescimento, o mais utilizado é o AIB (ácido indolbutírico), cujo efeito estimulante do enraizamento já foi comprovado para diversas espécies frutíferas, como ameixeira (MINDÉLLO NETO et al., 2006), pessegueiro (OLIVEIRA et al., 2005), umezeiro (Prunus mume) (MAYER et al., 2001), porta-enxerto de ameixeira 'Mirabolano' (Prunus cerasifera) (RAMOS et al., 2003) e porta-enxerto de citros (ANDRADE et al., 2003) entre outras.

Outro fator que pode influenciar no enraizamento de estacas de abacateiro é o modo de aplicação das estacas na solução hidroalcoólica, ocorrendo divergências na literatura. Existem procedimentos de tempo de imersão de 10 segundos (SILVEIRA et al., 2004), 20 segundos (BOURDEAUT, 1970) e de 24 horas (LA PEÑA, 1975).

O objetivo deste trabalho foi determinar a concentração de AIB e o tempo de imersão indicado para enraizamento de estacas herbáceas de abacateiro cv. Fuerte (híbrido guatemalense $x$ mexicana).

\section{METODOLOGIA}

O estudo foi conduzido na Embrapa Transferência de Tecnologia, em Canoinhas, Santa Catarina, em casa-de-vegetação equipada com sistema de nebulização intermitente, acionada por um programador de horário que controlava a abertura e o fechamento de uma válvula solenóide, regulada para um molhamento de 20 segundos a cada 15 minutos.

Ramos herbáceos de abacateiro cv. Fuerte (híbrido guatemalense $x$ mexicana) foram coletados em 10 de fevereiro de 2004, de plantas matrizes com um ano de idade e levados para laboratório onde foram selecionados aqueles com diâmetro entre 6 a $8 \mathrm{~mm}$ e $12 \mathrm{~cm}$ de comprimento, permanecendo no terço superior 3 folhas cortadas ao meio por estaca. $O$ corte na base da estaca foi em bisel. As estacas foram previamente pulverizadas com uma solução de captan $(0,25 \%)$ e, semanalmente, após o início do experimento.

As estacas foram tratadas com AIB nas concentrações de 0, 500, 1.000, 2.000 e $4.000 \mathrm{mg} \cdot \mathrm{L}^{-1}$. O método de aplicação das estacas na solução de AIB, de acordo com cada tratamento, foi por imersão rápida por 5 segundos e imersão lenta por 24 horas. Como testemunha foi utilizada água destilada (sem AIB). As doses de AIB utilizadas foram diluídas em $500 \mathrm{~mL}$ de álcool etílico e completadas seu volume até 1 litro, com água destilada. Após a aplicação do $\mathrm{AIB}$, as estacas foram plantadas em bandejas de poliestireno expandido com 72 células, num substrato de areia textura média, as quais foram deixadas para enraizar em casa-de-vegetação coberta com sombrite (50\% de sombreamento).

O delineamento experimental foi inteiramente casualizado, com quatro repetições e 10 estacas por repetição, num sistema fatorial $5 \times 2$ (concentrações de AIB $x$ tempo de imersão). Decorridos 185 dias da estaquia, as estacas foram retiradas das bandejas e foi avaliada a porcentagem de enraizamento.

Os resultados foram transformados em arc sen $\sqrt{x / 10 C}$, devido à falta de normalidade e homocedasticidade. Após a transformação, realizou-se a análise de variância e as médias foram comparadas pelo teste de Scott-Knott ao nível de $5 \%$ de probabilidade.

\section{RESULTADOS E DISCUSSÃO}

Para a porcentagem de estacas enraizadas houve interação significativa entre os fatores concentrações de AIB e o tempo de imersão. Observase que quando foi usado o tempo de 5 segundos de imersão, ocorreu enraizamento em todas as concentrações testadas com diferença significativa entre elas, excetuando as concentrações de 2.000 e $4.000 \mathrm{mg} \cdot \mathrm{L}^{-1}$. Com 5 segundos, a concentração de $500 \mathrm{mg} . \mathrm{L}^{-1}$ de AIB proporcionou os melhores resultados de enraizamento $(47,5 \%)$ (Tabela 1$)$. As estacas que não enraizaram, encontravam-se mortas no momento da avaliação. 
TABELA 1 - Porcentagem de estacas herbáceas enraizadas de abacateiro cv. Fuerte, em função do tempo de imersão e diferentes concentrações de AIB (mg.L-1) diluídas em solução hidro-alcoólica (1:1), com testemunha somente água ${ }^{(1)}$. CanoinhasSC, 2004.

\begin{tabular}{lrrrrr}
\hline Tempo de imersão & \multicolumn{5}{c}{ Concentrações de AlB $\left(\mathrm{mg} \cdot \mathrm{L}^{-1}\right)$} \\
\cline { 2 - 6 } & 0 & 500 & 1.000 & 2.000 & 4.000 \\
\hline 5 segundos & $22,5 \mathrm{~A} \mathrm{~d}$ & $47,5 \mathrm{~A} \mathrm{a}$ & $37,5 \mathrm{~A} \mathrm{~b}$ & $32,5 \mathrm{~A} \mathrm{C}$ & $30,0 \mathrm{~A} \mathrm{c}$ \\
24 horas & $27,5 \mathrm{~A} \mathrm{a}$ & $0,0 \mathrm{~B} \mathrm{~b}$ & $0,0 \mathrm{~B} \mathrm{~b}$ & $0,0 \mathrm{~B} \mathrm{~b}$ & $0,0 \mathrm{~B} \mathrm{~b}$ \\
\hline C.V. $(\%)$ & \multicolumn{5}{c}{17,24} \\
\hline
\end{tabular}

(1)Médias seguidas de mesma letra maiúscula, na coluna, e minúscula, na linha, não diferem significativamente entre si, ao nível de 5\% de probabilidade, pelo teste de Scott-Knott.

Verificou-se que com concentrações maiores do que $500 \mathrm{mg} \cdot \mathrm{L}^{-1}$ de AIB ocorreu diminuição na porcentagem de estacas enraizadas, principalmente nas concentrações de 2.000 e $4.000 \mathrm{mg}^{-\mathrm{L}^{-1}}$ de AIB. Provavelmente a diminuição na porcentagem de estacas enraizadas seja devido à concentração de AIB acima da necessária para estímulo ao enraizamento, ocasionando desbalanço hormonal nas estacas e desequilíbrio entre promotores e inibidores, conforme relataram Mohammed e Sorhaindo (1984). Com essas taxas de enraizamento, que podem ser consideradas satisfatórias, haja visto a dificuldade da espécie, devese descartar a hipótese da existência de um anel fibroesclerenquimático, que atuaria como barreira à emergência das raízes, além deste efeito morfológico ocorrer em maior grau em cultivares da raça antilhana (GOMES et al., 1973; REUVEVI e RAVIV, 1976) e a cultivar testada neste experimento ser um híbrido entre as raças guatemalense e mexicana. A utilização de estacas herbáceas também permite a obtenção de melhores respostas de enraizamento do que com estacas lenhosas ou semilenhosas, conforme já demonstrado para o caquizeiro (BASTOS et al., 2005). Estacas herbáceas dos porta-enxertos de videira 'Jales' e 'Campinas' também possibilitaram a obtenção de excelentes resultados de enraizamento (ROBERTO et al., 2004).

O enraizamento foi nulo quando a imersão das estacas ocorreu por 24 horas na solução hidroalcoólica, independentemente da concentração de AIB. Pode ter acontecido uma fitotoxidez provocada pelo efeito do álcool, já que a concentração de $50 \%$, utilizada para diluir o AIB é muito elevada. Na estaquia semilenhosa das cultivares Magnolia e Topsail de Vitis rotundifolia, a imersão lenta por 24 horas em soluções com ANA (ácido naftalenoacético) e AIB em concentrações de 250 a $1.000 \mathrm{mg} \cdot \mathrm{L}^{-1}$, também causou a morte de todas as estacas, apenas ocorrendo enraizamento nas testemunhas formadas pela solução hidro-alcoólica a 10\% (BIASI e BOSZCZOWSKI, 2004).

O longo tempo de permanência nas soluções com elevadas concentrações de auxina, também pode ter sido a causa da morte das estacas. La Peña (1975) utilizou o tempo de imersão por 24 horas para a estaquia de abacateiro, mas com concentrações de até $100 \mathrm{mg}^{-\mathrm{L}^{-1}}$ de AIB sem fitotoxidez. Na imersão lenta normalmente são obtidos melhores resultados com baixas concentrações de auxinas, variando de 50 a $200 \mathrm{mg} \cdot \mathrm{L}^{-1}$, conforme já verificado na estaquia semilenhosa de goiabeira (BIASI et al., 1998; PEREIRA et al., 1991). Na estaquia herbácea de pessegueiro das cultivares Delicioso Precoce, Jóia 1 e Okinawa tratadas com os métodos de imersão lenta em soluções diluídas (100 a $300 \mathrm{mg}^{-\mathrm{L}^{-1}}$ de AIB) por 24 horas e imersão rápida em soluções concentradas (1.250 a 3.750 mg. L-1 de AIB) por 5 segundos, de forma geral, o método de imersão rápida demonstrou melhores resultados (TOFANELLI et al., 2003).

\section{CONCLUSÃO}

A maior porcentagem de estacas enraizadas de abacateiro cv. Fuerte se obtém com a imersão das estacas por 5 segundos em solução com $500 \mathrm{mg} \cdot \mathrm{L}^{-1}$ de AIB.

\section{REFERÊNCIAS}

1. ANDRADE, R. A. de; MARTINS, A. B. G. Propagação vegetativa de porta-enxertos para citros. Revista Brasileira de Fruticultura, Jaboticabal, v. 25, n. 1, p. 134-136, 2003.

2. BASTOS, D. C.; PIO, R.; SCARPARE FILHO, J. A.; LIBARDI, M. N.; ALMEIDA, L. F. P. de; ENTELMANN, F. A. Enraizamento de estacas lenhosas e herbáceas de cultivares de caquizeiro com diferentes concentrações de ácido indolbutírico. Revista Brasileira de Fruticultura, Jaboticabal, v. 27, n. 1, p. 182-184, 2005.

3. BIASI, L.A.; BOSZCZOWSKI, B. Propagação por estacas semilenhosas de Vitis rotundifolia cvs. Magnolia e Topsail. Revista Brasileira de Agrociência, Pelotas, v. , n., p. 2004.

4. BIASI, L.A.; SÃO JOSÉ, A.R.; BILIA, D.A.C.; FORNASIERI, J.L. Influência do tipo de estaca na propagação vegetativa da goiabeira 'Supreme'. Revista Acadêmica, Curitiba, v. 9, n. 2, p. 11-16, 1998.

5. BOURDEAUT, J. Lê bouturage de l' avocatier em côte D' Ivoire. Fruits, Paris, v. 25, n.9, p.605-612, 1970

6. FROLICH, E.F.; PLATT, R.G. Use of etiolation technique in rooting avocado cuttings. California Avocado Society Yearbook, Saticoy, v.55, p.97-109, 1972. 
MENDÊLLO-NETO, U.R. et al. Propagação de abacateiro...

7. GOMES, R.E.; SOULE, J.; MALO, S.F. Anatomical aspects of avocado stem with reference to rooting. Proceedings of the American Society for Horticultural Science, Alexandria, v. 17, p. 23-28, 1973.

8. KADMAN, A.; BEN-YA'ACOV, A. A review of experiments on some factors influencing the rooting of avocado cuttings. California Avocado Society Yearbook, Saticoy, v.49, p. 67-72, 1965.

9. $\quad$ LA PEÑA, F.J. A de. El Aguacate. Madrid: Ministerio de Agricultura. 1975. $169 \mathrm{p}$.

10. MAYER, N. A.; PEREIRA, F. M.; NACHTIGAL, J. C. Propagação do umezeiro (Prunus mume Sieb e Zucc.) por estaquia herbácea. Revista Brasileira de Fruticultura, Jaboticabal, v. 23, n. 3, p. 673-676, 2001.

11. MINDÊLLO NETO, U. R.; TELLES, C. A.; BIASI, L. A. Enraizamento de estacas lenhosas de ameixeiras tratadas com ácido indolbutírico. Ciência rural, Santa Maria, v.36, n.2, p.448-452, 2006.

12. MOHAMMED, S.; SORHAINDO, C.A. Production and rooting of etiolated cuttings of West Indian and hybrid avocado. Tropical Agricultura, Trinidad e Tobago, v.61, n.3, p. 200-204, 1984.

13. OLIVEIRA, A. P. de; NIENOW, A. A.; CALVETE, E. O. Qualidade do sistema radicular de estacas semilenhosas e lenhosas de pessegueiro tratadas com AIB. Revista Brasileira de Fruticultura, Jaboticabal, v. 27, n. 2, p. 346-348, 2005.

14. PEREIRA, F.M.; PETRECHEN, E.H.; BENINCASA, M.M.P.; BANZATTO, D.A. Efeito do ácido indol butírico no enraizamento de estacas herbáceas de goiabeira (Psidium guajava L.) das cultivares 'Rica' e 'Paluma', em câmara de nebulização. Científica, Jaboticabal, v. 19, n. 2, p. 199-206, 1991.

15. RAMOS, J. D.; MATOS, L.E.S.; GONTIJO, T.C.A.; PIO, R.; JUNQUEIRA, K.P.; SANTOS, F.C. Enraizamento de estacas herbáceas de 'mirabolano' (Prunus cerasifera ehrn) em diferentes substratos e concentrações de ácido indolbutírico. Revista Brasileira de Fruticultura, Jaboticabal, v.25, n.1, p.189-191, 2003.

16. ROBERTO, S. R.; PEREIRA, F.M.; NEVES, C.S.V.J.; JUBILEU, B.S.;AZEVEDO, M.C.B. Enraizamento de estacas herbáceas dos porta-enxertos de videira 'Campinas' (IAC 766) e 'Jales' (IAC 572) em diferentes substratos. Ciência rural, Santa Maria, v.34, n.5, p.1633-1636, 2004

17. REUVEVI, O.; RAVIV, M. Foliar sprays to increase the rooting rate of avocado cuttings. Horticulturae, Israel, v.65, p. 37-39, 1976.

18. SILVEIRA, S.V. da; SOUZA, P.V.D. de; KOLLER, O.C. Propagação vegetativa de abacateiro por estaquia. Revista Brasileira de Fruticultura, Jaboticabal, v. 26, n.1, p.191-192, 2004.

19. TOFANELLI, M. B. D.; ONO, E. O.; RODRIGUES, J. D. Método de aplicação de ácido indolbutírico no enraizamento de estacas herbáceas de pessegueiro. Revista Brasileira de Fruticultura, Jaboticabal, v.25, n. 2, p.363-364, 2003.

Recebido em 25/05/2006 Aceito em 09/08/2006 